\title{
Cognitive Dysfunction in Early and Late Onset Schizophrenia:
}

\section{A Comparative Study}

\author{
Dr. Rajendra Kumar Sharma ${ }^{1}$, Supriya Sharma ${ }^{2}$
}

\section{ABSTRACT}

The aim of this present study was to assess the cognitive dysfunctions among early onset schizophrenia and Late onset schizophrenia. Methods: The study was conducted at Ranchi Institute of Neuro- Psychiatry and Allied Sciences (RINPAS), Kanke, Ranchi. Based on purposive sampling method a group of forty male schizophrenic patients between the age range of 18 to 42 years were taken twenty patients were early onset schizophrenia (18 to 30 years) and twenty patients were of late onset of schizophrenia (31 to 42) years who were diagnosed according to the DCR, ICD - 10 were selected from different words of RINPAS. Similarly twenty normal controls were selected from different localities of Ranchi. Results: Significant result found on different domains. A normal control on VAIS was better than schizophrenic groups, between the schizophrenics groups the late onset schizophrenics performance better than early onset schizophrenics patient. The performance of normal controls on WAPIS-PR was better than schizophrenic groups, between the schizophrenics groups the late onset schizophrenics performance better than early onset schizophrenics patient. The performance of normal on controls on WCST was better than schizophrenic groups, between the schizophrenics groups the late onset schizophrenics performance better than early onset schizophrenics patient. Late onset schizophrenic patients performed better than early onset schizophrenic patients, indicating that late onset schizophrenics are relatively less impaired than early onset schizophrenics, with respect of cognitive function, as measured by IQ and WCST performance.

\section{Keywords: Early and Late Onset Schizophrenia, Cognition}

The evidence has long been clear that schizophrenia is a disorder of the brain with genetic and neurodevelopment components, yet the precise nature of the brain pathology and genetic vulnerability remain unknown. In addition, there is remarkable heterogeneity among schizophrenia presentation, everyday functioning, treatment response, and course of illness.

\footnotetext{
${ }^{1}$ Consultant Clinical Psychologist, Counselor, Army public School Bhopal, Madhya Pradesh, India

${ }^{2}$ Consultants Special Educator \& Executive Director MANOVIKAS Rehabilitation-Center, India *Responding Author

(C) 2016, R Sharma, S Sharma; licensee IJIP. This is an Open Access Research distributed under the terms of the Creative Commons Attribution License (http://creativecommons.org/licenses/by/2.0), which permits unrestricted use, distribution, and reproduction in any Medium, provided the original work is properly cited.
} 


\section{Cognitive Dysfunction in Early and Late Onset Schizophrenia: A Comparative Study}

Indeed, in coining the modern term for this disorder, Eugen Bleuler spoke not of "Schizophrenia" such heterogeneity has led some to suggest that the term schizophrenia has itself outlived its usefulness (Howard, 1996). A more common approach has been to divide schizophrenia into subtypes. Attempts to devise a meaningful subtypes scheme are as old as the concept of schizophrenia itself. Kraepelin initially divided the disorder the disorder into hebephrenic, catatonic, and paranoid forms, and later, impart inspired by E. Bleular, he proposed an even more complex sub typing scheme. E. Bleuler (1911) proposed four major grouping based on symptoms (hebephrenia, catatonia, paranoid, and schizophrenia simplex) but also suggested the possibility of groupings based on periodicity etiology, severity of symptoms and perhaps most important age at onset.

\section{Early onset schizophrenia:}

Three-fourth of all schizophrenias begin with a prepsychoticprodromal phase, which lasts several times longer than the psychotic prophase. Since an extended pre-treatment course of schizophrenia, as mentioned at the outset, is associated with an unfavourable prognosis, the question arises how the early phases of schizophrenia can be made accessible to therapy. By suitable measures it might perhaps be possible to delay or even prevent the onset of the first episode. It might be that part of schizophrenias actually comes to a halt before the first positive symptoms appear. Such cases are probably encountered as sub-threshold conditions with primarily negative or nonspecific symptomatology in epidemiological family studies (Bassett et al, 1994; Mater et al., 1993).+

Deficits in social development come about in the prodromal phase. At this stage failure to reach the expected social status plays a greater role than steps of social decline, which gain in relevance after the main social roles have been acquired. Due to their lower age of onset and probably also their more frequent socially negative illness behaviour males are socially more disadvantaged in the early course of schizophrenia compared with females. In contrast, symptomatology and, surprisingly, type of onset does not seem to have any significant influence on the crudely measured two year outcome of social disability.

Whether age and level of social development at onset also play a role in determining long-term social outcome has not yet been demonstrated conclusively. But very likely they do not. In the long run the level of social development a person has achieved by the beginning of the disorder is bound to loose some of its effect, while in the further course the severity of the disease, individual coping patterns and different environments are likely to increase their influence and this contribute to the enormous variability of schizophrenia outcomes. For a better understanding of the very different consequence and consequences of the disorder it seems necessary to study not only a heterogeneous disease model, but also the interaction between social, emotional and cognitive development and the manifestations of the illness over time bearing in mind that causality may run either way. 


\section{Cognitive Dysfunction in Early and Late Onset Schizophrenia: A Comparative Study}

This term should not be confused with early onset schizophrenia label that has historically been used to refer to patients who develop schizophrenia in childhood or early adolescence.

\section{Late onset schizophrenia:}

The late onset schizophrenia although not a formal diagnostic category separate from regular schizophrenia, is intended to refer to those patient who meet the diagnostic criteria for schizophrenia but where clinical symptoms first emerged in middle age or late age.

An implicit hypothesis of those who assert that late onset schizophrenia cannot be "true schizophrenia" because it is presumed to lack neurodevelopment origins is the notion that late onset schizophrenia reflects more recently acquired or emergent neuropathology. Certainly behavioral changes ultimately reflect parallel changes in the brain, so on some level the onset of psychosis in any schizophrenia patient must be associated with some parallel changes in brain activity. However, there is no consistent evidence for recently emergent neuropathology in late onset schizophrenia patient.

Studies of late-onset schizophrenia began with Manfred Bleuler, who personally examined 126 patients whose illness began after the age of 40 years. These late - onset cases constituted $15 \%$ of the schizophrenia patients he examined $4 \%$ of the patients had an onset after 60 . About $50 \%$ of the patients with late - onset schizophrenia had symptoms that were indistinguishable from those seen in schizophrenic patients with the more typical younger age at onset. Bleuler's age cutoff of 40 years influenced the German literature. Subsequent reports in the English literature used either 55 or 60 years of age as the dividing line and adopted the term "late paraphrenia" to both distinguish the illness from chronic schizophrenia and emphasize its clinical similarities with the condition described by Kraepelin. This was an unfortunate choice, however, since Kraepelin had never regarded late age at, onset as a feature of paraphrenia. Moreover, the concept of paraphrenia - experiencing hallucinations and delusions without deterioration or disturbance of affective response, this distinguishing the disorder form dementia praecox had been discredited. Driven by the early emergence in Europe of geriatric psychiatry as a distinct subspecialty, as well as the apparent syndromic coherence of late paraphrenia, including female preponderance, abnormal premorbid personality and social functioning and deafness, the late paraphrenia concept was readily adopted and included in ICD - 9 .

In the United States, the inclusion within DSM III - R of a separate category for patients whose illness emerged after age 45 was largely in reaction to the unsatisfactory upper limit for age at onset that had hitherto prevailed for a diagnosis of schizophrenia. With what represented unprecedented transatlantic agreement (in late-onset schizophrenia terms), neither ICD - 10 nor DSM - IV contained separate code able diagnoses for late-onset schizophrenia. The current "official” view would seen to be that all cases that satisfy diagnostic criteria for schizophrenia, regardless of onset age, fall into the same illness category. Ghosts of the earlier diagnoses 


\section{Cognitive Dysfunction in Early and Late Onset Schizophrenia: A Comparative Study}

remain, however DSM - IV mentions that cases of schizophrenia with onset after age 45, while similar to early onset cases, are associated with a higher ratio of women, better occupational and marital histories, more paranoid delusions and hallucinations, and less disorganization and negative symptoms. The presence of sensory deficits is also mentioned among those with the “oldest age at onset”.

Corey-Bloom et al. (1995) found that patients with late onset schizophrenia had larger ventricular and thalamic volumes compared with earlier onset patients. In addition, when we examined age at onset as a continuous variable, we found that thalamic and caudate volumes, as well as performance on neuropsychological measures of flexibility/abstraction ability, were significant predictors of age at onset.

In beginning to address the question of whether changes in cognitive functioning occur among older patient with schizophrenia relative to younger patient, cross-sectional studies can provide are not relatively more impaired than younger patient in their performance on cognitive tests than it is unlikely that cognitive change has occurred. As can be seen from the research presented in this section this simple question has proven somewhat complicated to answer.

Zorilla et al (2000) found that 116 outpatient with schizophrenia had no more evidence of greater age related changes than would be expected with normal aging, as indexed by the performance of non-psychiatric comparison subject, in their Dementia Rating Scale (DRS) scores with subject ranging in age from 40 to 80 years. These patients had significant levels of impairment, with as many as $70 \%$ being found to meet clinical criteria for Neuropsychological deficit.

Cognitive impairment has been known to be a feature of schizophrenia since the illness was first described in a systematic manner. Beginning with the first clinical description of the illness, impairments in cognitive functioning have been noted and described. Since that time it has been discovered that patient with schizophrenia perform very poorly on many different tests of cognitive neuropsychological tests and experimental measures of attention and information processing. This is not, however, a new finding. In 1944, Hunt and Cofer reviewed the first 50 years of research on cognitive impairment in schizophrenia, covering many of the same areas of deficit that receive research attention today. Since the functional importance of the cognitive impairments of schizophrenia has become better understood, there has been a surge of interest in cognitive impairments, including the course and treatment of these impairments. (Green et al, 2000).

Borod, et al, (2000) have ability of patients with schizophrenia to identify individual emotions. Overall, all patients were significantly less accurate than healthy volunteers in recognizing all emotional stimuli, but were relatively less impaired in the identification of happiness, 


\section{Cognitive Dysfunction in Early and Late Onset Schizophrenia: A Comparative Study}

particularly from faces. Others have also demonstrated greater accuracy in the recognition of happiness than negative emotions by patients with schizophrenia.

Mohamed et al, (1999); Bilder et al, (2000) have concluded that an important component of schizophrenia involves compromised performance in most of the cognitive domains: working memory, executive function, verbal declarative memory, and attention. Although not all schizophrenia patients show impaired cognitive functioning, often a generalized deficit is observed. However, no specific "neuro cognitive profile” exists for schizophrenia.

Weickert et al, (2000) found subgroups of in-patients with chronic schizophrenia with different cognitive profiles based on change in IQ from premorbid values as cognitive impairment is a significant determinant of social and occupational function.

Addington \& Addington, (2000); Gold et al, (2002) have concluded that it is important to ascertain whether such cognitive heterogeneity is representative of schizophrenia in general and specifically if it is present at illness onset. This will contribute to an understanding of the extent and timing of cognitive impairment and inform early rehabilitation strategies. Therefore, we examined cognitive heterogeneity in individuals presenting to mental health services with first episode schizophrenia.

Weickert et al, (2000) found that a quarter of their patients had a low premorbid IQ, compared with a tenth in our study. Further a large group with schizophrenia, they were self-selecting and it is possible that more patients with lower rather than higher IQ declined to take part in the study. Other studies find that low IQ is over-presented as far back as childhood in those destined to develop schizophrenia.

Thompson et al, (2001) have found that if memory and executive deficits both occur during psychotic illness it is important to note whether the two arise independently. Two previous hypotheses have been suggested. Repeated structural imaging in early onset schizophrenia has shown grey matter loss spreading from parietal through temporal prefrontal regions. Suggesting that in the early stages of psychosis, memory might be more impaired than 'frontal' function such as attention - shifting.

Nelson et al, (1990), Goldberg et al, (1993), Weickert et al, (2000), Kremen et al, (2001) have found that patient who demonstrated a decline in IQ also showed considerable impairment on tests of memory and executive function. The difference between this subgroups and those with no evidence of reduced IQ could not be explained by more severe psychotic symptoms or by the type of antipsychotic medication. Almost half (46\%) of this subgroup had become psychotic during the 12 months preceding presentation and the duration of untreated psychosis did not difference between this group and those with normal preserved IQ. This suggests that 


\section{Cognitive Dysfunction in Early and Late Onset Schizophrenia: A Comparative Study}

deterioration in IQ from normal levels is not attributable to a longer course of illness. Thus, in a substantial number of our patients, global deterioration in intellectual function appears to have occurred as an early manifestation of the illness.

The finding at first presentation of deterioration in IQ from normal premorbid levels suggests that individuals can be on a normal cognitive trajectory during development. Studies of army conscripts, in which direct measures of premorbid IQ were obtained, found that low IQ is a prominent feature in adults prior to the onset of psychosis.

Rabinowitz et al, (2000) Gunnel et al, (2002) have suggests that cognitive function is declining during the years immediately preceding the onset of psychosis.

Fuller et al, (2002) in a longitudinal in people who went on to develop schizophrenia, found that scholastic aptitude actually increased between the ages of 9 and 13 years, prior to a precipitous decline over the following four years. Pantelis et al, (2003 b) have proposed a neurodevelopmental model of psychosis that predicts greater impairment in those cognitive functions that develop later. They argue that an early - developing function such as memory has a greater chance to recover through brain plasticity, while those developing nearer the age of onset of psychosis (such as executive functions) are less likely to recover function.

Gunnell et al, (2002) have concluded that the IQ measures might not have been sensitive enough to show association with age at onset in the presence of a strong contribution of chronicity. In a large study of military conscripts, an association was found between poor intellectual functioning at 18 years of age and onset of schizophrenia about five years later.

Glahn et al, (2003) found that with high/average preserved IQ at first episode of schizophrenia show a specific impairment in working memory. Our spatial working memory task measures the ability to remember the location of a number of tokens previously retrieved while searching for new tokens. This suggests that a disturbance of executive function, of the type required to hold information in memory while performing other cognitive operation, is present in all patients independent of IQ. In a recent family study there was a dose-response relationship between the degree of spatial working memory impairment and increasing genetic predisposition to schizophrenia, suggesting that impaired spatial working memory may 'constitute an effective endo-phenotype' of the disorder.

Tuulio-Henriksson et al, (2004) in the context of an epidemiological study of Finnesh families having at least one child with schizophrenia, these workers assessed 239 patients with tests of IQ, memory and executive function. Age at onset was significantly and specifically associated with performance of the California Verbal Learning Test (CVLT), in that poorer word list learning and delayed recognition memory were both associated with a younger age at onset. The 


\section{Cognitive Dysfunction in Early and Late Onset Schizophrenia: A Comparative Study}

patients in the study had been ill for a mean of 12 years, but when the researchers controlled statistically for the possible contributions of age at assessment, duration of illness and severity of illness, the age at onset effect remained the same. Thus, impaired memory may be a risk factor for - rather than a consequence of - an earlier onset. These finding supports that of Jeste et al, (1998) who found a significant correlation between age at onset and learning, measured by a composite memory score derived from a number of test including the CVLT, in 82 people with schizophrenia.

Kreman et al, (2000); Keefe et al, (2005) have reported that individuals with schizophrenia score between one-half to one-and-a-half standard deviations below the control mean in a wide variety of neuropsychological domains including attention, memory, intelligence, motor speed, spatial ability, executive functioning and verbal fluency, thus showing a generalized deficit. Some patients do not show impairments compared with controls, but it may be that also their cognitive functioning has deteriorated from the premorbid level.

Haggond, Patrick (2005) has found that subjective experience of conscious intention is a key component of our mental life. Philosophers studying 'conscious free will' have discussed whether conscious intentions could cause, but modern neuroscience rejects this idea of mind body causation. Instead, recent findings suggest that to conscious experience of intending to act arises from preparation for action in frontal and parietal brain areas. Intentional actions also involve a strong sense of agency, a sense of controlling events in the external world. Both intention and agency result from the brain process for predictive motor control, not merely from retrospective inference.

\section{Significance of the study:}

This research is more significant for managing the patients with the help of these tests one can analyze the severity of the cognitive dysfunctions among early onset schizophrenics patients and late onset schizophrenics patients and this evaluation paves the way to the management of such patient. Limited research has been conducted on the population of early onset schizophrenics and late onset schizophrenic. The present research effort is an afforded in the light of exploring the same.

\section{METHODOLOGY}

Sample:

Based on purposive sampling method a group of forty male schizophrenic patients between the age ranges of 18 to 42 years were taken in the present study. Twenty patients were of early onset schizophrenia (18 to 30 years) and twenty patients were of late onset of schizophrenia (31 to 42 years) Patients were diagnosed according to the DCR, ICD - 10 and have been selected from different words of RINPAS. Similarly twenty normal controls were selected from different localities of Ranchi. 


\section{Cognitive Dysfunction in Early and Late Onset Schizophrenia: A Comparative Study}

Tools for the Assessments:

The following tools have been administered.

- $\quad$ Socio - demographic and clinical data sheet

- $\quad$ Verbal Adult Intelligence Scale (VAIS).

- $\quad$ Wechsler Adult Performance Intelligence Scale (WAPIS - PR).

- Wisconsin card sorting test (WCST)

\section{Socio Demographic and clinical data sheet:}

A semi -structured Performa have been used for recording details about the patients such as age, education, marital status, occupation, age of onset of illness etc.

\section{Verbal Adult Intelligence Scale - (VAIS): Dwarka Pershad, S.K. Verma:}

This test is adaptation of original WAIS - R that has been standardized by Dr. Dwarka Pershad \& Dr. Santosh Kumar Verma in (1989) on Indian population. The purpose of the test is to assess the verbal adult intellectual performance of subjects.

Verbal Adult Intelligence Scale (VAIS) consisting of four subtests i.e. Information, Digit Span, Arithmetic and Comprehension.

\section{Wechsler Adult Performance Intelligence Scale (WAPIS - PR): Prabha Ramalingaswamy (1974):}

This test is adaptation of original WAIS - $\mathrm{R}$ that has been standardized by Prabha Ramalingaswamy. The purpose of the test is to assess the performance intelligence of adult subjects.

Wechsler Adult Performance Intelligence Scale (WAPIS) consisting of Picture Completion, Digit Symbol, Block Design, Picture Arrangement and Object Assembly subtests.

\section{Wisconsin Card Sorting Test (WCST):}

It is a clinical neuropsychological test originally developed by Grant and Berg (1948) to assess abstract reasoning ability and an ability to shift cognitive strategy in response to changing environmental contingencies. Similar to other measures of executive functioning WCST requires strategic, planning, organized searching, utilizing environmental feedback to shift cognitive sets, directing behaviour towards achieving a goal and modulating impulsive responding.

WCST contains four stimulus cards and two identical decks of sixty-four response cards with figure of varying forms, colour and number. First deck of response card is given to the subjects with instruction to match each consecutive card from the deck with one of the four stimulus cards. Once the client has made a specified number of consecutive correct matches, the sorting principles changes, and WCST proceeds in this manner through a number of shifts in set. 


\section{Cognitive Dysfunction in Early and Late Onset Schizophrenia: A Comparative Study}

WCST provides objective not only score of overall success but also specific sources of difficulty on the task. (e.g. inefficient initial conceptualization, failure to maintain cognitive set, perseveration and inefficient learning across stages of the test).

To make finding more comparable across studies Heaton and Colleagues provided a standard method of administering and scoring WCST according to which fourteen scores are yielded.

\section{Procedure:}

Subjects of the schizophrenic groups were selected from different wards and the OPD of Ranchi Institute of Neuro - Psychiatry and Allied Sciences, Kanke, Ranchi. Semi structured clinical data sheet were used. To assess the intellectual performance of the subjects Indian Adaptation of Verbal Intelligence Test (VAIS) have been used and for the assessment of performance Intelligence (WAPIS), has been used. WCST have been administered as per the standard procedure.

\section{RESULTS}

Table 1 .: Socio - Demographic Profile of Normal control (20) early onset (20) and late onset (20).

\begin{tabular}{|c|c|c|c|c|c|c|c|}
\hline \multicolumn{2}{|c|}{ Variable } & $\begin{array}{c}\text { Normal } \\
\text { Group } \\
\text { mean } \pm \\
\text { SD/n }(\%)\end{array}$ & $\begin{array}{c}\text { Early Onset } \\
\text { Schizophrenia } \\
\text { mean } \pm \text { SD/n } \\
(\%)\end{array}$ & $\begin{array}{c}\text { Late Onset } \\
\text { Schizophrenia } \\
\text { mean } \pm \text { SD/n } \\
(\%)\end{array}$ & $\chi^{2} / \mathbf{F}$ & df & $\begin{array}{c}\text { Level of } \\
\text { significance }\end{array}$ \\
\hline \multicolumn{2}{|c|}{ Age } & $27.40 \pm 6.93$ & $27.85 \pm 3.06$ & $39.10 \pm 4.17$ & 35.20 & - & NS \\
\hline $\begin{array}{l}\text { Marital } \\
\text { Status }\end{array}$ & $\begin{array}{c}\text { Unmarried } \\
\text { Married }\end{array}$ & $\begin{array}{c}13(65) \\
7(35)\end{array}$ & $\begin{array}{c}8(40) \\
12(60)\end{array}$ & $\begin{array}{l}5(25) \\
15(7)\end{array}$ & $6.65 *$ & 2 & 0.05 \\
\hline Education & $\begin{array}{c}\text { Up to Matric } \\
\text { Above } \\
\text { Matric }\end{array}$ & $\begin{array}{c}6(30) \\
14(70)\end{array}$ & $\begin{array}{c}15(75) \\
5(25)\end{array}$ & $\begin{array}{c}14(70) \\
6(30)\end{array}$ & $46.58^{* * *}$ & 4 & 0.001 \\
\hline Occupation & $\begin{array}{c}\text { Unemployed } \\
\text { Semi skilled } \\
\text { Skilled }\end{array}$ & $\begin{array}{c}3(15) \\
11(55) \\
6(30)\end{array}$ & $\begin{array}{c}1(5) \\
15(75) \\
4(20)\end{array}$ & $\begin{array}{c}1(10) \\
12(60) \\
6(30)\end{array}$ & $20.00 * *$ & 6 & 0.01 \\
\hline Domicile & $\begin{array}{c}\text { Rural } \\
\text { Semi Urban } \\
\text { Urban }\end{array}$ & $\begin{array}{c}2(10) \\
1(5) \\
17(85)\end{array}$ & $\begin{array}{c}15(75) \\
4(20) \\
1(5) \\
\end{array}$ & $\begin{array}{c}13(65) \\
4(20) \\
3(15) \\
\end{array}$ & $33.51 * * *$ & 4 & 0.001 \\
\hline SES & $\begin{array}{l}\text { LSES } \\
\text { MSES } \\
\text { HSES }\end{array}$ & $\begin{array}{c}3(15) \\
16(80) \\
1(5)\end{array}$ & $\begin{array}{c}16(80) \\
3(15) \\
1(5)\end{array}$ & $\begin{array}{c}15(75) \\
5(25) \\
---\end{array}$ & $22.48 * * *$ & 4 & 0.001 \\
\hline
\end{tabular}

It is clear from Table 1.a. which gives descriptive information about the socio-demographic characteristics of entire sample, which was divided into three groups - Normal control, early 


\section{Cognitive Dysfunction in Early and Late Onset Schizophrenia: A Comparative Study}

onset schizophrenia and late onset schizophrenia. The mean age of normal controls, early onset, and late onset were $27.40 \pm 6.93,27.85 \pm 3.06$ and $39.10 \pm 4.17$ respectively. It is clear from the table that there is no significant difference among three groups.. Though, there are marked mean difference between the age of early onset and late onset of schizophrenics. Late onsets of schizophrenics were older than that of early onset of schizophrenics.

Table 2: Performance of various groups on VAIS:

\begin{tabular}{|c|c|c|c|c|c|}
\hline Variable & $\begin{array}{c}\text { Normal (a) } \\
\text { Mean } \pm \text { SD }\end{array}$ & $\begin{array}{c}\text { Early Onset } \\
\text { Schizophrenia } \\
\text { (b) } \\
\text { Mean } \pm \text { SD }\end{array}$ & $\begin{array}{c}\text { Late Onset } \\
\text { Schizophrenia } \\
\text { (c) } \\
\text { Mean } \pm \text { SD }\end{array}$ & $\begin{array}{c}\text { F } \\
\text { value }\end{array}$ & Post hoc test \\
\hline Information & $109.70 \pm 8.55$ & $98.00 \pm 19.07$ & $104.65 \pm 21.82$ & 2.17 & $\begin{array}{c}\mathrm{a}>\mathrm{b} \\
\mathrm{a}>\mathrm{c}\end{array}$ \\
\hline Digit Span & $93.70 \pm 8.31$ & $78.40 \pm 12.67$ & $88.35 \pm 7.32$ & 12.76 & $\begin{array}{c}\mathrm{a}>\mathrm{b}^{*} \\
\mathrm{a}>\mathrm{C}^{*}\end{array}$ \\
\hline Arithmetic & $98.50 \pm 19.81$ & $77.65 \pm 14.30$ & $82.55 \pm 16.75$ & 1.06 & $\begin{array}{c}\mathrm{a}>\mathrm{b} \\
\mathrm{a}>\mathrm{c}\end{array}$ \\
\hline Comprehension & $96.80 \pm 11.27$ & $74.25 \pm 13.06$ & $75.00 \pm 17.03$ & 16.73 & $\begin{array}{c}\mathrm{a}>\mathrm{b}^{* *} \\
\mathrm{a}>\mathrm{C}^{* *}\end{array}$ \\
\hline Verbal I.Q. & $99.10 \pm 7.31$ & $82.85 \pm 11.31$ & $86.75 \pm 11.45$ & 13.81 & $\begin{array}{l}\mathrm{a}>\mathrm{b}^{*} \\
\mathrm{a}>\mathrm{c}^{*}\end{array}$ \\
\hline
\end{tabular}

$* \mathrm{P}<0.05 * * \mathrm{P}<0.01$

Results have been presented in table 2, which shows the difference performance between normal controls, early onset schizophrenics and late onset schizophrenics on VAIS. It has been concluded that normal subjects performed better than that of early onset schizophrenics and late onset schizophrenics on information subtest of VAIS, and difference was statistically significant at 0.05 level. When the performance of early onset schizophrenics and late onset schizophrenics have been compared on the same subtest of VAIS, it has been observed that late onset schizophrenics, performed better in comparison to early onset of schizophrenics. When the performance was analyzed on Digit Span test it has been noticed that normal control subjects performed better than both early onset schizophrenics and late onset schizophrenics. Difference was found significant at 0.05 level. While comparing the performance of early onset schizophrenics and late onset schizophrenics it has been concluded that late onset schizophrenics performed significantly better than that early onset schizophrenics and difference was significant at 0.05 level of statistical measure. Now coming to the performance on arithmetic subtest of VAIS it has been noticed that normal control subjects performed better in comparison to early onset schizophrenics and late onset schizophrenics. Late onset schizophrenic's patients performed superior than early onset schizophrenics. On comprehension subtest of VAIS trend was similar that is normal control subjects performed better in comparison to clinical groups

(C) The International Journal of Indian Psychology, ISSN 2348-5396 (e)| ISSN: 2349-3429 (p) | 73 


\section{Cognitive Dysfunction in Early and Late Onset Schizophrenia: A Comparative Study}

(early onset schizophrenics and late onset schizophrenics). Difference was found statistically significant at 0.01 level. While comparing the performance early onset schizophrenics and late onset schizophrenics it has been concluded that the performance of late onset schizophrenics was superior than that of early onset schizophrenics. While computing the overall verbal I.Q. of the normal control subjects and schizophrenics groups, it has been experienced that normal control subjects obtained superior verbal I.Q. in comparison to early onset schizophrenics and late onset schizophrenics. Late onset schizophrenics patients showed superior verbal I.Q. than early onset schizophrenics patients, which indicates that early onset schizophrenics had shows more cognitive dysfunction in comparison to late onset schizophrenics patients and normal control subjects. Late onset schizophrenics patients showed lesser cognitive dysfunction in comparison to early onset schizophrenics but were significantly more impaired on cognitive functions than that of normal control subjects.

Table 3, Performance of various groups on WAPIS - PR:

\begin{tabular}{|c|c|c|c|c|c|}
\hline Variable & $\begin{array}{c}\text { Normal (a) } \\
\text { Mean } \pm \text { SD }\end{array}$ & $\begin{array}{c}\text { Early Onset } \\
\text { Schizophrenia } \\
\text { (b) } \\
\text { Mean } \pm \text { SD }\end{array}$ & $\begin{array}{c}\text { Late Onset } \\
\text { Schizophrenia } \\
\text { (c) } \\
\text { Mean } \pm \text { SD }\end{array}$ & $\begin{array}{c}\text { F } \\
\text { value }\end{array}$ & Post hoc test \\
\hline $\begin{array}{c}\text { Picture } \\
\text { completion }\end{array}$ & $15.45 \pm 1.63$ & $11.60 \pm 1.81$ & $11.90 \pm 2.02$ & 27.29 & $\begin{array}{l}\mathrm{a}>\mathrm{b}^{* * *} \\
\mathrm{a}>\mathrm{C}^{* * *}\end{array}$ \\
\hline $\begin{array}{c}\text { Digit } \\
\text { Symbol }\end{array}$ & $13.85 \pm 1.46$ & $11.60 \pm 1.81$ & $10.20 \pm 1.90$ & 22.40 & $\begin{array}{l}\mathrm{a}>\mathrm{b}^{* * *} \\
\mathrm{a}>\mathrm{C}^{* * *}\end{array}$ \\
\hline $\begin{array}{c}\text { Block } \\
\text { Design }\end{array}$ & $7.45 \pm 2.08$ & $4.05 \pm 0.82$ & $4.35 \pm 0.93$ & 35.92 & $\begin{array}{l}\mathrm{a}>\mathrm{b} * * * \\
\mathrm{a}>\mathrm{C}^{* * *}\end{array}$ \\
\hline $\begin{array}{c}\text { Picture } \\
\text { Arrangement }\end{array}$ & $10.50 \pm 0.88$ & $6.70 \pm 1.03$ & $6.85 \pm 1.63$ & 61.56 & $\begin{array}{l}\mathrm{a}>\mathrm{b} * * * \\
\mathrm{a}>\mathrm{C}^{* * *}\end{array}$ \\
\hline $\begin{array}{c}\text { Object } \\
\text { Assembly }\end{array}$ & $7.50 \pm 1.05$ & $4.55 \pm 0.68$ & $5.60 \pm 1.46$ & 36.02 & $\begin{array}{l}\mathrm{a}>\mathrm{b} * * * \\
\mathrm{a}>\mathrm{C}^{* * *}\end{array}$ \\
\hline \multicolumn{2}{|c|}{\begin{tabular}{c} 
P.Q. \\
\hline \multicolumn{2}{|c|}{$102.40 \pm 9.61$}
\end{tabular}} & $83.85 \pm 5.36$ & $87.15 \pm 7.66$ & 32.64 & $\begin{array}{l}\mathrm{a}>\mathrm{b}^{* * *} \\
\mathrm{a}>\mathrm{C}^{* * *}\end{array}$ \\
\hline \begin{tabular}{c} 
I.Q. \\
\hline
\end{tabular} & $100.80 \pm 4.27$ & $83.50 \pm 6.93$ & $87.20 \pm 7.31$ & 41.50 & $\begin{array}{l}\mathrm{a}>\mathrm{b} * * * \\
\mathrm{a}>\mathrm{C}^{* * *}\end{array}$ \\
\hline
\end{tabular}

$* * * \mathrm{P}<0.001$

Table 3.b. shows the performance of various groups on Weschsler Adult Performance Intelligence Scale (WAPIS - PR). It has been observed that normal subjects performed better than early onset schizophrenic patients and late onset schizophrenic patients on picture completion subtest of WAPIS - PR and difference was significant at 0.001 level of statistical measures. While comparing the performance of two clinical groups it has been noticed that early onset schizophrenics performed poorly in comparison to late onset schizophrenic patients.

(C) The International Journal of Indian Psychology, ISSN 2348-5396 (e)| ISSN: 2349-3429 (p) | 74 


\section{Cognitive Dysfunction in Early and Late Onset Schizophrenia: A Comparative Study}

Performance of digit symbol subtest of WAPIS - PR indicates that normal control subjects performed superior than that of early onset schizophrenic patients and late onset schizophrenics patients. Difference was significant statistically at 0.001 level. Late onset schizophrenics performed poorly than early onset schizophrenic, patients but difference was not significant statically. While analyzing the performance on block design subtest of WAPIS -PR similar result have been witnessed like normal control subjects performed better than that of early onset schizophrenics and late onset schizophrenic patients and difference was again significant at 0.001 level of statistically. Performance of all three groups (normal control, early onset schizophrenics and late onset schizophrenic patients) on picture arrangement indicated that normal control subject performed better than early onset schizophrenics and late onset schizophrenic patients, and difference was statistically significant at 0.001 level. Similar pattern have been observed while comparing the performance on object assembly subtest of WAPIS PR. The performance of early onset schizophrenics was poorer than late onset schizophrenic patients and normal subjects. While combining together all subtest of WAPIS - PR it has been noticed that normal control subjects performed better than of early onset schizophrenics and late onset schizophrenic patients on WAPIS - PR. Early onset schizophrenic patients performed poorly in comparison to normal control subjects. Early onset schizophrenic patients and late onset schizophrenic patients by combining their verbal intelligence quosent and performance quosent overall I.Q. have bee computed. It has been observed that subjects belonging to normal group showed average level of I.Q. where as the I.Q. of late onset schizophrenics and early onset schizophrenic patients were falling in the category of borderline intelligence. Looking at the performance of the various groups (normal control subjects, early onset schizophrenics and late onset schizophrenic patients) on Wechsler Adult Performance Intelligence Scale-PR, it can be concluded that early onset schizophrenic patients showed more cognitive dysfunctions in comparison to normal control subjects and late onset schizophrenic patients. Late onset schizophrenic patients performed better than early onset schizophrenic patients, but poorer than that of normal control subjects on Wechsler Adult Performance Intelligence Scale - PR.

Table 4: Performance of normal control subjects, early onset schizophrenics patients and late onset schizophrenics patients Wisconsin Card Sorting test (WCST):

\begin{tabular}{|c|c|c|c|c|c|}
\hline Variable & $\begin{array}{c}\text { Normal (a) } \\
\text { Mean } \pm \text { SD }\end{array}$ & $\begin{array}{c}\text { Early Onset } \\
\text { Schizophrenia } \\
\text { (b) } \\
\text { Mean } \pm \text { SD }\end{array}$ & $\begin{array}{c}\text { Late Onset } \\
\text { Schizophrenia } \\
\text { (c) } \\
\text { Mean } \pm \text { SD }\end{array}$ & $\begin{array}{c}\text { F } \\
\text { value }\end{array}$ & Post hoc test \\
\hline $\begin{array}{c}\text { No of trails } \\
\text { administered }\end{array}$ & $101.50 \pm 17.28$ & $127.65 \pm 1.56$ & $125.10 \pm 12.96$ & 26.57 & $\begin{array}{c}\mathrm{a}<\mathrm{b}^{* * *} \\
\mathrm{a}<\mathrm{b}^{* * *}\end{array}$ \\
\hline $\begin{array}{c}\text { Total no. of } \\
\text { correct resp. }\end{array}$ & $68.30 \pm 5.32$ & $57.25 \pm 19.12$ & $56.90 \pm 14.96$ & 4.08 & $\begin{array}{c}\mathrm{a}>\mathrm{b}^{*} \\
\mathrm{a}>\mathrm{c}^{*}\end{array}$ \\
\hline $\begin{array}{c}\text { Total no. of } \\
\text { errors. }\end{array}$ & $33.90 \pm 14.94$ & $70.40 \pm 19.73$ & $68.20 \pm 20.27$ & 24.55 & $\begin{array}{c}\mathrm{a}<\mathrm{b}^{* * *} \\
\mathrm{a}<\mathrm{c}^{* * *}\end{array}$ \\
\hline
\end{tabular}

(C) The International Journal of Indian Psychology, ISSN 2348-5396 (e)| ISSN: 2349-3429 (p) | 75 
Cognitive Dysfunction in Early and Late Onset Schizophrenia: A Comparative Study

\begin{tabular}{|c|c|c|c|c|c|}
\hline Variable & $\begin{array}{l}\text { Normal (a) } \\
\text { Mean } \pm \text { SD }\end{array}$ & $\begin{array}{c}\text { Early Onset } \\
\text { Schizophrenia } \\
\text { (b) } \\
\text { Mean } \pm \text { SD }\end{array}$ & $\begin{array}{c}\text { Late Onset } \\
\text { Schizophrenia } \\
\text { (c) } \\
\text { Mean } \pm \text { SD }\end{array}$ & $\begin{array}{c}\text { F } \\
\text { value }\end{array}$ & Post hoc test \\
\hline \% Errors & $30.90 \pm 9.58$ & $54.95 \pm 15.47$ & $52.70 \pm 15.44$ & 18.51 & $\begin{array}{l}\mathrm{a}<\mathrm{b} * * * \\
\mathrm{a}<\mathrm{c} * * *\end{array}$ \\
\hline $\begin{array}{l}\text { Perseverative } \\
\text { response(PR) }\end{array}$ & $22.45 \pm 10.29$ & $60.70 \pm 38.16$ & $42.65 \pm 23.92$ & 10.29 & $\begin{array}{l}\mathrm{a}<\mathrm{b} * * * \\
\mathrm{a}<\mathrm{C} * * *\end{array}$ \\
\hline$\% \mathrm{PR}$ & $21.35 \pm 6.93$ & $47.35 \pm 29.79$ & $21.35 \pm 6.93$ & 13.74 & $\begin{array}{l}\mathrm{a}<\mathrm{b} * * * \\
\mathrm{a}<\mathrm{C} * * *\end{array}$ \\
\hline $\begin{array}{c}\text { Perseverative } \\
\text { errors (PE) }\end{array}$ & $21.15 \pm 9.03$ & $49.70 \pm 30.82$ & $44.75 \pm 22.83$ & 8.99 & $\begin{array}{l}\mathrm{a}<\mathrm{b} * * * \\
\mathrm{a}<\mathrm{c} * * *\end{array}$ \\
\hline$\% \mathrm{PE}$ & $20.30 \pm 5.87$ & $38.80 \pm 24.01$ & $35.00 \pm 17.76$ & 6.17 & $\begin{array}{l}\mathrm{a}<\mathrm{b}^{*} \\
\mathrm{a}<\mathrm{c}^{*}\end{array}$ \\
\hline $\begin{array}{c}\text { Non } \\
\text { perseverative } \\
\text { response(NPR) }\end{array}$ & $8.45 \pm 7.56$ & $20.55 \pm 14.89$ & $20.05 \pm 13.36$ & 6.14 & $\begin{array}{l}a<b^{*} \\
a<c^{*}\end{array}$ \\
\hline$\% N P R$ & $7.25 \pm 5.88$ & $16.05 \pm 11.43$ & $16.25 \pm 9.50$ & 6.19 & $\begin{array}{l}\mathrm{a}<\mathrm{b}^{*} \\
\mathrm{a}<\mathrm{c}^{*}\end{array}$ \\
\hline $\begin{array}{c}\text { Conceptual } \\
\text { level } \\
\text { response(CLR) }\end{array}$ & $62.05 \pm 8.35$ & $31.20 \pm 22.40$ & $32.85 \pm 20.37$ & 18.30 & $\begin{array}{l}\mathrm{a}>\mathrm{b}^{* * * *} \\
\mathrm{a}>\mathrm{c} * * *\end{array}$ \\
\hline \% CLR & $60.55 \pm 12.33$ & $24.25 \pm 17.38$ & $25.60 \pm 15.86$ & 35.98 & $\begin{array}{l}\mathrm{a}>\mathrm{b} * * * \\
\mathrm{a}>\mathrm{c} * * *\end{array}$ \\
\hline $\begin{array}{c}\text { No. of } \\
\text { categories } \\
\text { completed. }\end{array}$ & $5.15 \pm 1.66$ & $1.65 \pm 1.81$ & $1.95 \pm 2.01$ & 22.33 & $\begin{array}{l}\mathrm{a}>\mathrm{b}^{* * * *} \\
\mathrm{a}>\mathrm{c}^{* * *}\end{array}$ \\
\hline $\begin{array}{c}\text { Trials taken to } \\
\text { complete } 1^{\text {st }} \\
\text { categories }\end{array}$ & $13.50 \pm 5.05$ & $13.95 \pm 14.72$ & $21.35 \pm 31.26$ & 0.956 & $\mathrm{a}<\mathrm{c}^{*}$ \\
\hline $\begin{array}{c}\text { Failure to } \\
\text { maintain set }\end{array}$ & $17.61 \pm 3.92$ & $12.05 \pm 5.53$ & $17.51 \pm 9.12$ & 1.87 & $\mathrm{a}>\mathrm{b} *$ \\
\hline $\begin{array}{c}\text { Learning to } \\
\text { learn }\end{array}$ & $17.62 \pm 8.66$ & $11.14 \pm 16.63$ & $0.00 \pm 0.00$ & 24.47 & $\begin{array}{l}\mathrm{a}>\mathrm{b}^{* * * *} \\
\mathrm{a}>\mathrm{c} * * *\end{array}$ \\
\hline
\end{tabular}

$* \mathrm{P}<0.05, * * * \mathrm{P}<0.001$

Result presented in table 4 depicted that early onset schizophrenics patients shows more cognitive dysfunctions than normal control subjects as number of trails administered to them was significantly higher in comparison to normal control subjects difference was significant at 0.001 level of statistical significant.

(C) The International Journal of Indian Psychology, ISSN 2348-5396 (e)| ISSN: 2349-3429 (p) | 76 


\section{Cognitive Dysfunction in Early and Late Onset Schizophrenia: A Comparative Study}

\section{CONCLUSION}

The performance of normal controls on VAIS was better than schizophrenic groups, between the schizophrenics groups the late onset schizophrenics performance better than early onset schizophrenics patient. The performance of normal controls on WAPIS-PR was better than schizophrenic groups, between the schizophrenics groups the late onset schizophrenics performance better than early onset schizophrenics patient. The performance of normal on controls on WCST was better than schizophrenic groups, between the schizophrenics groups the late onset schizophrenics performance better than early onset schizophrenics patient. Late onset schizophrenic patients performed better than early onset schizophrenic patients, indicating that late onset schizophrenics are relatively less impaired than early onset schizophrenics, with respect of cognitive function, as measured by IQ and WCST performance.

\section{Acknowledgments}

The author appreciates all those who participated in the study and helped to facilitate the research process.

\section{Conflict of Interests}

The author declared no conflict of interests.

\section{BIBLIOGRAPHY}

Addington, J., \& Addington, D., (2000) Neurocognitive and social functioning in schizophrenia: a 2.5 year follow-up study. Schizophrenia Research, 44, 47-56.

Berman, H., Viegner, B., Amalia, M., Allan, E., et al (1997) Differential relationship between positive and negative symptoms and neuropsychological deficits in schizophrenia. Schizophrenia Research 25:1-10.

Blanchard, J.J., \& Neale, J.M., (1994) The neuropsychological signature of schizophrenia: generalized or differential deficit? American Journal of Psychiatry 151, 40-48.

Bornstein, RM., Leason, M.. (1985) Effects of localized lesions on the verbal concept attainment test. Journal of Clinical and Experimental Neuropsychology. 7: 421-429.

Braff, D.L., Heaton, R.K., Kuck, J., Cullum, M., Moranville, J., Grant, I., Zisook, S., (1991) The generalized pattern of neuropsychological deficits in outpatient with chronic schizophrenia with heterogeneous Wisconsin Card Sorting Test Results. Archives of General Psychiatry. 48: 891-898.

Corey-Bloom, J., Jernigan, T., Archibald, S., et al (1995) Quantitative magnetic resonance imaging of the brain in late-life schizophrenia. Am J psychiatry 152:447-449.

Crow, T. J., MacMillan, J. F., Johnson, A. L., \& Johnstone, E. C., (1986) A randomized controlled trial of prophylactic neuropletic treatment. Brit, J. Psychiatry 148: 120-127.

Dieci, M., Vita, A., Silenzi, C., Caputo., (1997) A Non- selective Impairment of Wisconsin Card Sorting Test performance in patients with schizophrenia. 25: 33-42. 


\section{Cognitive Dysfunction in Early and Late Onset Schizophrenia: A Comparative Study}

Drewe, E. A., (1974) The effect of type and area of brain lesion on Wisconsin Card Sorting Test Performance. Cortex 10: 159-170.

Egan, M. F., Goldberg, et al (2001). Relative risk for cognitive impairments in siblings of patients with schizophrenia. Bialogical Psychiatry 50, 98-107.

Eggers, C., \& Bunk, D., (1997) The long term course of childhood onset schizophrenia; a 42year followup. Schizophrenia Bulletin, 23, 105-117.

Franke, P., Maier, W., Hain, C., \& Klingler, T., (1992). Wisconsin Card Sorting Test: an indicator of vulnerability to schizophrenia? Schizophrenia Research 6. 243-249.

Frith, C., (1996) Neuropsychology of schizophrenia: what are the implication of intellectual and experiental abnormalities for the schizophrenia, British Medical Bulletin 52, 618-626.

Goldberg, T. E., Gold, J.M., Greenberg, R., Griffin, S., Schulz, S.C., Picker, D., Kleinman, J.E.(1993) Contrasts between patients with affective disorders and patients with schizophrenia on a neuropsychological test batter. Am J Psychiatry: 150 :1355-1362.

Goldberg, T., Hyde, T., Kleinman, J., et al (1993) Course of schizophrenia: neuropsychological evidence for a staic encephalopathy. Schizophrenia Bulletin, 19. 797-804.

Goldstein, G.. (2000) Cognitive heterogeneity in psychopathology: the case of schizophrenia. In: Veron PA(Ed.). The Neuropsychology of individual differences. San Diego: Academic Press 1994. In: Sharma T and Harvey P. (Eds.). Cognition in Schizophrenia Impairments, Importance and treatment strategies. United Kingdom: Oxford University Press.

Goldstein, K., Brain, (1943) concussion : Evaluation of the after effects by special tests. Disease of the Nervous System 4: 3-12.

Green, M. F., (1998) Schizophrenia From a Neurocognitive Perspective: Probing the Impenetrable Darkness. Boston, MA, Allyn \& Bacon.

Green, M.F., (2000) Schizophrenia from a neurocognitive perspective: Probing the impenetrable darkness. Boston: Allyn and Bacon 1998. in: Sharma, T., and Harvey, P.. (Eds). Cognition is Schizophrenia - Impairments, importance and treatment strategies. United Kingdom: Oxford University Press.

Hafner, H., Riecher-Rossler, et al (2001) First onset and early ymptomatology of schizophrenia. Eur. Arch. Psychiatry Clin. Neurosci.fs 24 D 242:109-118.

Heaton, R. K., (1981) Wisconsin card sorting Test Manual, Odessa, Psychological Assessment Resources.

Heinrichs, R. W., \& Zakzanis, K. K., (1998) Neurcocgnitive deficit in schizophrenia : a quantitative review of the evidence. Neuropsychology 12, 426-445.

Howard, R., Cox, T., el al (1995) White matter abnormalities in the brains of patients with late paraphrenia and the normal community living elderly. Biol Psychiatry 38:86-91.

Jeste, D. V., Lacro, J. P., et al (1993) Treatment of late-life schizophrenia with neuroleptics. Schizophr Bull 19:817-830.

Jeste, D. V., McAdams, L. A., Palmer, B. W., et al (1998) Relationship neuropsychological and MRI measures to age of onset of Schizophrenia. Acta Psychiatr Scand 98:156-164. 


\section{Cognitive Dysfunction in Early and Late Onset Schizophrenia: A Comparative Study}

Jeste, D. V., Symonds, L. L., Harrism Mjkjo,mJ, et al (1997) Nondementia nonpraecox dementia praecox? Late - onset schizophrenia. An J Psychiatry 5:302-317.

Kirwin, P. D., \& Berman, K. F., (1988). Performance of schizophrenic patients on putative Neuropsychological tests of frontal lobe function. International Journal of Neuroscience 51-58.

Kraeplin, E., Damentia, Praecox, and Paraphrenia, (2000)Sharma T and Harvey P. (Eds.). Cognition in Schizophrenia - Impairments, importance and treatment strategies. United Kingdom: Oxford University Press.

Lohr, J. B., Alder, M., Flynn., K., et al (1997) Minor physical anomalies in older patients with late-onset schizophrenia, early onset schizophrenia, depression, and Alzheimer's disease. Am J Geriatr Psychiatry 5:318-323.

Luria, A. R., (1966) The Higher Cortical Functions in man. New York, Basic.

Mandal, K. M., Pandey, G., Singh, K. S., et al (1992) Hand preference in India. International Journal of Psychology 27: 433-442.

Mekenna, P. J., Tamlyn, D., Lund, C. E., Mortimer, A . M., Hammond, S., \& Baddeley, A.. D., (1990). Amnesic syndrome in schizophrenia. Psychological Medicine 20, 967-972.

Milner, B., (1969) Effects of different brain lesions on card sorting. Archives of neurology 9: 90100.

Mohamed, S., Paulsen, J. S., O” Leary, D., Arndt, S., \& Andreasen, N., (1999) Generalized cognitive deficits in schizophrenia: a study of first -episode patients. Archives of General Psychiatry 56,749-754.

Ottesen, J. P., Hoizman, P. S., (1976) Cognitive controls and psy chopathology J abnorm Psychol $87: 212-225$.

Overall, J. E., Gorham, D. R., (1988) The Brief Psychiatric Rating Scale (BPRS). Recent developments in ascertaining and scaling. Psychopharmacological Bulletin 24 (1): 93-97.

Palmer, B. W., McClure, F. S., Jeste, D. V., (1993) Schizophrenia in late life: findings challenge traditional concept. Harv Rev Psychiatry 9:51-58.

Parellada, (1994) Regional cerebral blood flow changes in prefrontal in prefrontal area. Psychiatric Research 55: 131 - 139.

Pershad, D., and Verma, S. K., (1998) Translation and adaptation of WAIS-R verbal scale in Hindi in the concept and assessment of intelligence. National Psychological Corporation, Agra.

Pope, H. G, Lipinski, J. D., (1978) Diagnosis in schizophrenia and manicdepressive illness. Archivees of General Psychiatry 35 : 811-828.

Ragland, J. D., Censists, D. M., Gur, R. C., Glahn D.C., Gallacher, F., Gur, R. E., (1996) Assessing Declarative memory in schizophrenia using Wisconsin Card Sorting Test stimuli: the Paired Associate Recognition Test. Psychiatry Research 60: 135-145.

Remalinga, Swami, P., (1974). The measurement of intelligence among adult Indians. published in India by MANASAYAN ,New Delhi. 


\section{Cognitive Dysfunction in Early and Late Onset Schizophrenia: A Comparative Study}

Seltzer, J., Conrad, C., Cassens, G., (1994) Neuropsychological profiles in schizophrenia: paranoid versus undifferentiated distinctions. Schizophrenia Research. 27L 131-138.

Stratta, P., Daneluzzo, E., Prosperini, P., Bustini, M., Casacchia, M., Ross A. , (1997) Is Wisconsin Card Sorting Test Performance related to 'working memory' capacity? Schizophrenia Research. 27: $11-19$.

Stuss, D. T., Levine, B., Alexander, M. P., Hong, J., Palumbo, C., Hamer, L., Murphy, K. J., Izukawa, D., (2000) Wisconsin Card Sorting Test performance in patients with focal frontal and posterior brain damage: effects of lesion location and test structure on separable cognitive processes. Neuropsychological 38: 388-402.

Taylor, M. A., and Abrams, R., (1984) cognitive impairment in schizophrenia. American Journal of Psychiatry, 141,196-201.

Thompson, P. M., Vidal, C., Giedd, J. N., Gochman, P., Blumenthal, J., Nicolson, R., Toga, A. W., \& Rapoport, J. L., (2001) Mapping adolescent brain change reveals dynamic wave of accelerated gray matter loss in very early-onset schizophrenia, Proceedings of National Academy of Sciences of the United States of America 98, 11650-11655.

Zorilla, et al (2000) A Cognitive deficits in schizophrenia: evidence for a final common pathway disorder. Acta Psychiatrica Scandinavica 97: 351-357.

How to cite this article: R Sharma, S Sharma (2016), Cognitive Dysfunction in Early and Late Onset Schizophrenia: A Comparative Study, International Journal of Indian Psychology, Volume 3, Issue 4, No. 63, ISSN 2348-5396 (e), ISSN: 2349-3429 (p), DIP: 18.01.101/20160304, ISBN: 978-1-365-32518-2 